\title{
BENIGN MAMMARY TUMORS AND INTESTINAL TOXEMIA*
}

By William Seaman Batnbridge, M.C., U. S. N. R. F., New York, N. Y.

$\mathrm{T}$

HE present paper purposes to record a series of twenty-five cases of abnormal mammary changes apparently caused by autointoxication. When these cases are seen in their early stages the breast condition is often overlooked; when they have developed into a more easily recognized state, frequently a diagnosis of malignant disease is made.

Each of the cases reported herein suffered from a coexistant chroili intestinal toxemia, and the amount of poisoning was reflected, in many instances, in the degree of change in the mammary tissue. When the autointoxication was relieved the breasts either markedly improved or returned entirely to the normal.

These cases classify themselves, more or less, into three groups. 1. Those with a condensation or lobular induration of the upper, outer quadrants of the breasts, usually along the edge of the large pectoral muscle, and where the dependent breast drags on the upper axillary margin. This occurs in both mammæ, but more frequently in the left. Such terms as "toxic breasts," "Iumpy breasts" or "stasis lumps" are descriptive of this condition. 2. Those cases that have, in addition to the above, and in the same region, localized degeneration with adenomata or cystomata. 3. Those that have an abnormal discharge from the nipple in conjunction with one or the other of the above conditions.

The diminishing of the gastrointestinal fermentation by diet, digestives, intestinal antiseptics, high alkaline colonic irrigations, and certain physiotherapeutic measures, is of distinct value. The use of these agents, together with a support to the breasts and a proper uplifting abdominal corset, often result in a complete disappearance of the breast lumps or tumors. However, some of the cases require surgical intervention of the underlying abdominal condition before the toxic poisoning is sufficiently relieved as to noticeably benefit the breasts.

In those cases where there is a cyst or adenoma in addition to a general Iobular condition of the breasts, the removal of the growth and the correction of the intestinal stasis, by medical or surgical means, often result in the mammæ becoming completely normal. A preliminary lessening of the general toxic condition, in some cases, materially helped in locating the real existing benign neoplasm, and hence it was made possible to save a considerable amount of curable breast tissue. By this means the patients were saved the mental and physical shock of an unnecessary amputation.

*Read at the Thirty-third Annual Meeting of the Americar Association of Obstetricians, Gynecologists, and Abdominal Surgeone, held at Atlantic City, N. J., September 20-22, 1920. 
The majority of the following cases had marked chronic intestinal toxemia without any apparent accompanying pelvic disorder; a few had, in addition, complicating pathology: Five cases were cured without operation. Fifteen cases were cured by surgical relief of the chronic intestinal stasis, without operative interference of the mammæ. One case was cured by the removal of an adenoma from a generally lumpy breast, with an abdominal section for the underlying intestinal pathology. Three cases were cured by the removal of an adenoma or cystoma from a toxic breast, and by the preliminary and the after treatment for the intestinai toxemia. One case is that of toxic breasts which had been removed; the underlying condition not having been recognized.

CASE 1.-I. I, ; age thirty-five; female; single. First seen May 12, 1919. Constipa. tion with usual symptoms of intestinal stasis; backache. On examination, found floating right kidney; general enteroptosis; mass of feces in lower colon; considerable gas in ascending and transverse colon; marked lumpy condition in upper, outer quadrant left breast. Preseribed tonie, laxatives, uplifting corset belt; special abdominal exercises, and general hygienic regime. June, 1920: Patient in excellent health; constipation relieved; no longer any lumps in breast. September 1920, passed examination to enter training school for nurses of large metropolitan hospital.

CASE 2.-E. S.; age thirty-three; female; single. First seen September, 1898. Marked constipation; frequent attacks of intestinal gas; distinet lumps in upper, outer quadrant of left breast; nipple normal. Very much woried about cancer. Prescribed diet, eatharties, and support to breasts, with very careful and frequent examination. Six months after treatment was begun lumps in breasts disappeared. For some years, patient noticed that if she became constipated and had "indiges. tion," there was a return of the lumpy condition. This was relieved by thorough catharsis. August, 1920: Breasts perfectly normal.

CASE 3.-J. L.; age thirty; female; single. First seen January, 1919. Subacute attack of rheumatie fever; feet extremely swollen; painful; intestinal indigestion; headaches; nausea; marked constipation. On examination found intestinal stasis; large lumps in both breasts; enlarged glands of neck; swelling of feet and ankles. Prescribed diet; high alkaline colonic irrigations; salicylates, for a short time, catliartics, with physiotherapy as able to take it. Scptcmber 1920: Under treatment, swelling and pain in joints of feet and elsewhere gradually disappared. Lumps in breasts entirely gone after two months. Twice she allowed herself to become consti. pated and to be indiscreet with diet and at both times noticed a soreness and distinct Iumpy condition of breasts, which disappeared upon resorting to careful treatment.

CASE 4.-W. R.; age twenty-eight; female; married. First seen November 27, 1906. Rectal abseess and cyst of perineum removed. In 1919 complained of intestinal gas; loss of weight; constipation; soreness of breasts, worried about cancer. On exaninution, found gastroplosis; ascending colon and hepatic flexure clogged with fecal matter; considerable gas; distinct lumpy condition throughout breasts, more marked in upper, outer quadrant. Preseribed abdominal and breast supports; laxatives; high alkaline colonic irrigations several times a week; diet; tonic; special exercise. June, 1920: Patient stated she was no longer a "nervous wreck"; when careful of diet and bowels there is no soreness in breasts. Considers herself well. August, 1920: Excellent condition; breasts normal.

CASE 5.-A. G.; age forty-eight years; female; married. First seen December 9, 1918. Complained of pain and discomfort in left bruast. On exumination, found 
breasts very lairge, dependent, and the inner quadrant of left one slightly lobulated; no real tumor formation. Prescribed breast support; laxatives, with usual hygienic regime and careful watching. June, 1920: Lumpy condition of breasts entirely relieved-still a little soreness; constipation improved.

CASE 6.-A. B.* ; age twenty-five; female; widow. First seen February 23, 1916. March, 1915, severe pain right iliae fossa ; morphine preseribeds; several recurrences; constipation. Since August, 1915, constant bloody discharge from left breast; later distinct lump developed. Radical amputation advised by several surgeons. Diagnosis of cancer made by several of them. On examination, found distinct tenderness right iliac fossa; abdominal gas; lumpy condition in upper quadrant of left breast; on deep pressure, nipple exuded bloody serum. Advised surgical interforcnec for abdominal condition and that breast be kept under careful surveillance. Operation, March 11, 1916: Large, pendulous cecum; dilated terminal ileum; incompetent ileoceeal valve; many abdominal bands and adhesions. Conditions corrected. (See Fig. 1.) August, 1920: Exeellent general condition; breasts normal; no discharge

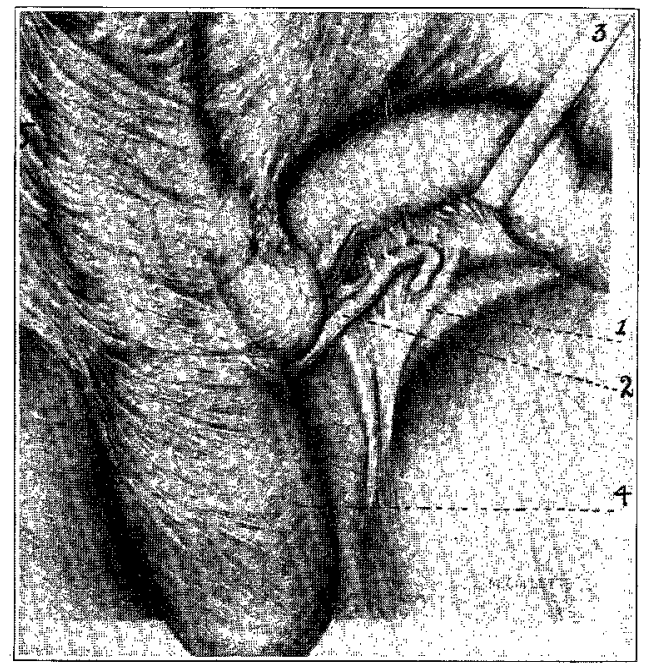

Fig. 1.-T. Tleopelvic band. 2. Kinked appendix attached to ileopelvic band. 3. Blunt retractor holding ileum upward. 4. Pendulous cecum, 5. Pericolic bands, so-called "Jackson menbrane."

since sixth day after operation. One month previous to my examination she saw a physician in the South who pronounced her "100 per cent perfect."

CASE 7.-C. H.†; age forty-one; female; married. First seen May 27, 1914. For a year enlarged right breast with constant pain; amputation advised by several surgeons. For many years atttacks of pain in regions of stomach and appendix. On examination, found dependent, lumpy breasts; nipples not retracted; pain over epigastrium on pressure; chronic appendix; intestinal stasis. Advised surgeon who referred patient for an opinion, to operate upon abdomen and to keep breasts under observation. Abdominal operation performed and diagnosis confirmed. No breast operation. June, 1920: Report by surgeon-patient's general health good; bronsts normal.

CaSe 8.-C. C.末; age twenty-t̂wo; female; single. First seen March 1, 1913. Marked neurasthenia; constant nausea; vomiting and dizziness. No satisfactory im-

*Case reported in part, in Woman's Med. Jour., May, 1917.

$\dagger$ Case reported in part in: Conservation of Human Breast, Internat. Jour. Surg., July, 1915.

\$Case reported in part: Am. Jour, Obst. and Dis. Women and Children, February, 1917. 
provement after nine months medical treatment under care of gastrointestinal special. ists. On examination found enlarged stomach; visceroptosis; mobile cecum; distinct ohain of humps extending down axillary line into substance of breasts. Operation, March 12, 1913: Marked cnteroptosis; drag on duodenum by bands to transverse colon; mobile cecum, acting as bueket to retain fecal matter, dragging on posterior wall of abdomen, pulling over peritoneum and hanging into true pelvis; many abdominal bands and adhesions. Conditions corrected so far as possible. (See Fig 2.)

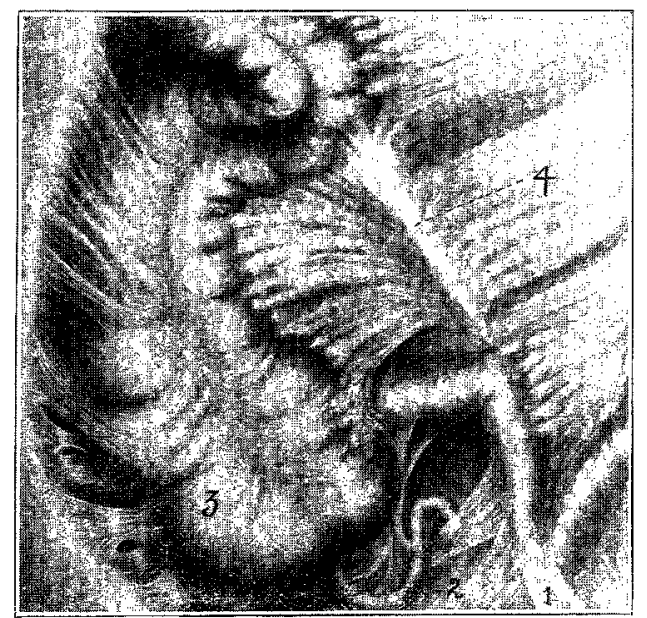

Fig. 2.- I. Ileal obstruction by bands. 2. Adherent ana kinked appendix. 3. Mobile cecum. 4. Thickened portion of mesocolon along line of mechanical stress.

Advised abdominal support and light brassiere for a time, with careful observation of breasts. July, 1920: Breasts perfectly normal; no nausea or vomiting; excellent ullysical and mental condition.

Case 9.-G. W.; age thirty; female; married. First seen January 25, 1917. For many years acute attacks of "indigestion", with pain in left side; vomiting; fever; hoadaches; abdominal gas; loss of weight. On examination, found lumpy condition in upper, outer quadrants both breasts; chronic intestinal stasis. Operation, February 12, 1917: Great omentum ađherent to right lateral wall of abdomen; two bands

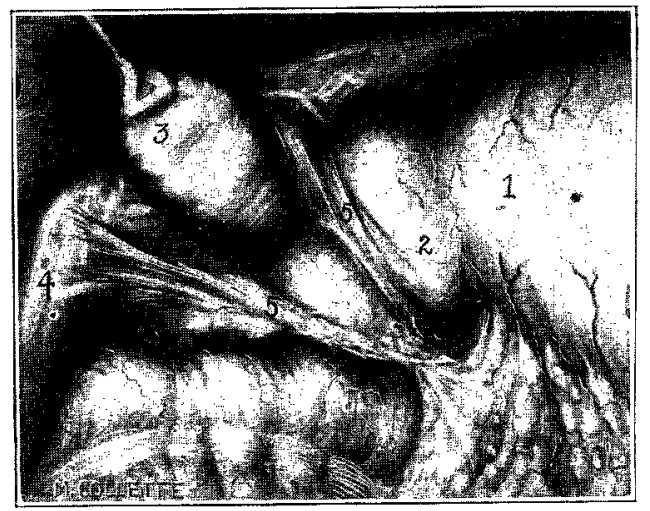

Fig. 3.-r. Stomach. 2. Dilated first portion duodenum. 3. Gall tladder held up by rubber covered forceps. 4. Liver. 5. Bands across duodenum from gastrocolic omentum to liver. 
across duodenum, one to pylorus and other to transverse colon; band of adhesions twisting junction of small and large bowel; rotating and mobile cecum with divertieulum; tense band from posterior wall of abdomen attached to bowel, causing point

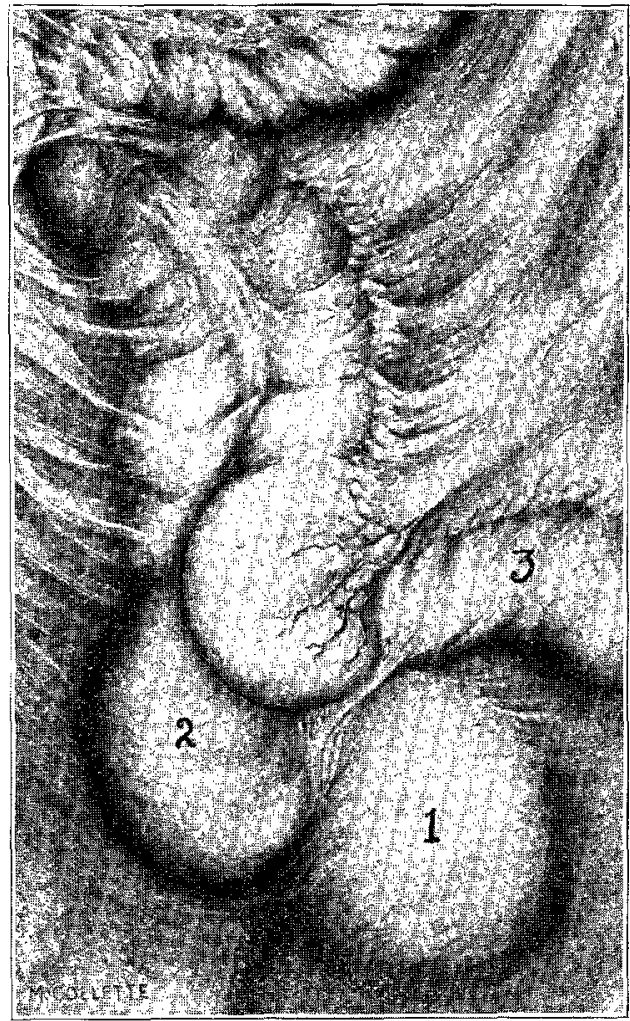

Fig. 4-I. Cecal diverticulun. 2. Rotated, tobile cecum. 3. Ileum.

of obstruction. Conditions corrected. (See Figs. 3 and 4.) July, 1920: Patient in excellent condition; pain, indigestion, vomiting, ete., relievcd; brcasts normal; lumps entirely disappeared.

CASE 10.-H. K.*; age twenty-five; female; single. First seen April 10, 1916. In 1914 had appendix removed; lost twenty-three pounds since then; troubled with gas; nausea; vomiting; abdominal discomfort; "at times kidneys do not work for" a whole day." On examination found diffuse psoriasis of extremities and body; al:dominal gas; dilated and prolapsed cecum; tenderness over terminal ileum; lumpy breasts. Operation, April 14, 1916: Adhesions from apex to base of gall bladder, indenting duodenum; extending towards stomach; band from transverse colon, alrost causing obstruction of duodenum; duodenojejunal kink; dilated duodenum; band across ascending colon causing partial obstruction; mobile and dilated cecum. Operative conditions corrected. (See Figs. 5, 6, 7.) July, 1920: Patient reported

*Case reported in part, in Medical Record, and Medical Press' and Circular, London, April, 1920.

Previonsly, I have reported cases of like nature, where the clinical symptoms simulated attacks of gallstones or acute inflammation of the gall bladder. Release of the band as shown in above drawing completely relieved symptoms. It is gratifying to observe that since I have applicd "pscudocholclithiasis" and "pseudocholecystitis" as entities, others have been employing the same terms. 
by letter from Coblenz, Germany. Physical condition most satisfactory; lumps in breasts entirely gone; psoriasis improved, but persists.

CASE 11.-J. M.; age forty-two; female; married. First seen October 5, 1917. Pain in back and right, lower abdominal quadrant; tenderness in epigastrium; usual symptoms of intestinal toxenia wilh constipalion. Oụ exanination found nterine

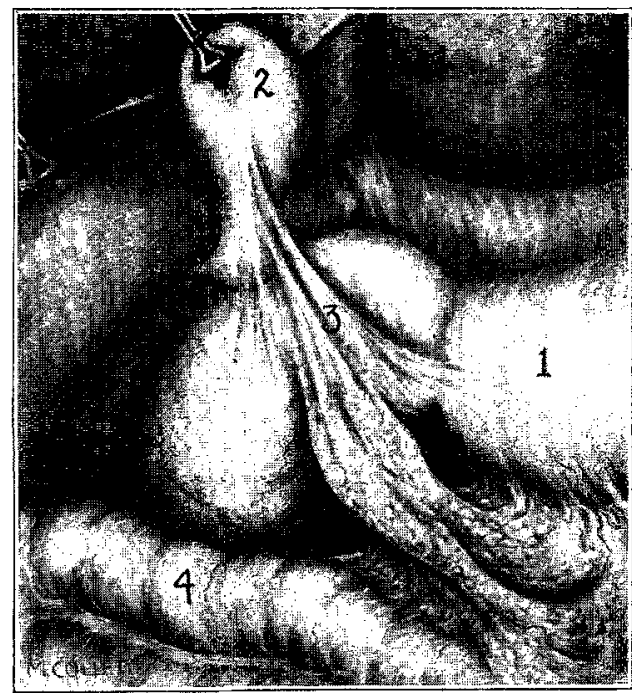

Fig. 5.-I. Stomach. 2. Gall bladder elevated by forceps. 3. Fxposed band from base of gall bladder, across to and indenting duodenum, and attached to transverse colon below. Trac tion on transverse colon caused kinking and twisting of ducts, resulting in retention of bile in gall bladder. 4. Transverse colon.

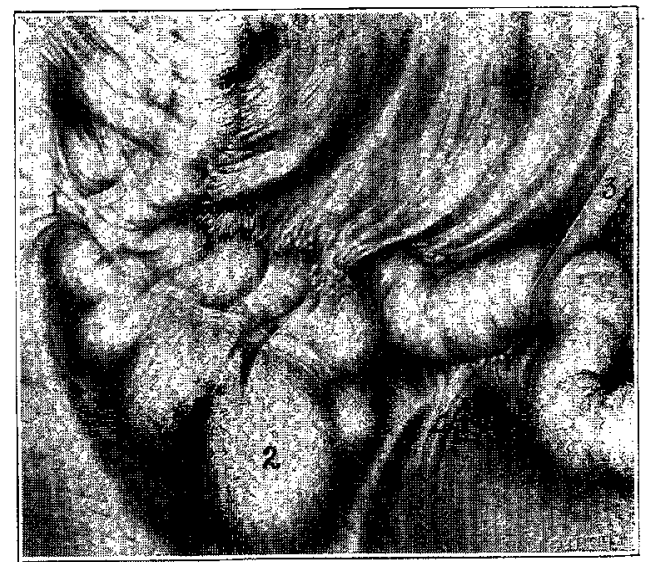

Fig. 6.-T. Band across ascending colon causing partial obstruction. 2. Mobile, dilated cecum. 3. Elunt retractor holding up dilated ileutn. 4. Early stages of development of an ileopelvic band.

polyp; cystocele; perineal laceration; chronie appendix; ileal stasis; marked lumpy condition upper, outer quadrant left breast. Operation, Oetober 11, 1917: Chronically inflamed and kinked appondix; adhesions around great omentum and gall bladder. Pelvic and abdominal conditions corrected. July, 1920: Excellent physical condition; constipation much improved and easily controlled by mild laxatives; no longer any lumps in breast. 
CAse 12.-Van B.; age twenty-six; female; married. First seen August 18, 1919. For many years "stomach trouble with bilious colic"; attacks of pain right upper" quadrant of abdomen, oxtending to back; recently more marked and more frequent. On examination found dilated gall bladder; chronic intestinal stasis; lumps in upper, cuter quadrants both breasts. Operation, September 19, 1919: Adhesions and bands

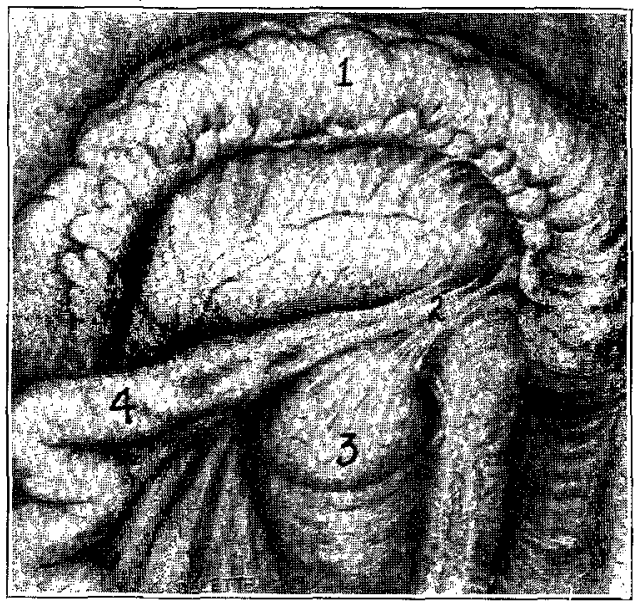

Fig. 7.-1. Transverse colon held up, exposing under surface of transverse mesocolon. 2. Duodenojejunal kink. 3. Dilated duodenum. 4. Jejunum.

right upper quadrant corrected; inflamed and thickened gall bladder with stones in eystie duct removed. Patient's condition was such it was deemed inadvisable to attack right lower quadrant. Preseribed uplifting eorset; dict; cathartics. July, 1920: Patient free from attacks of abdominal pain; stasis symptoms relieved; breasts normal; lumpy condition disappeared; gain of weight; general condition greatly improved.

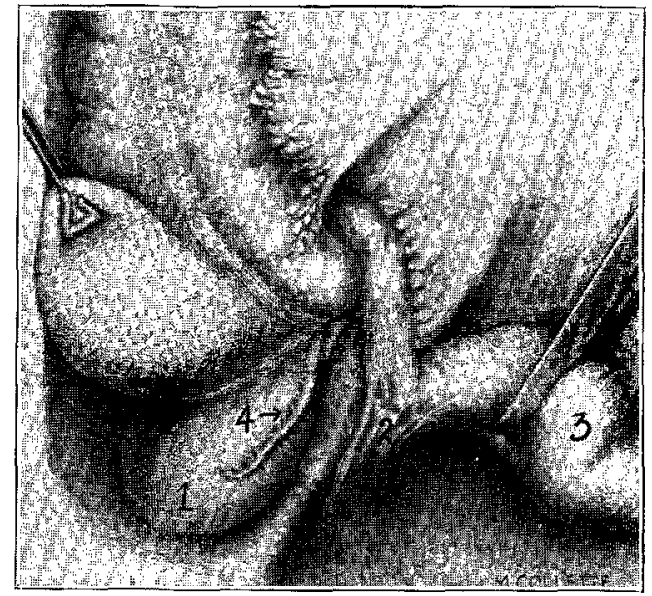

Fig. 8.- I. Retrocecal pouch. 2. Mleopelvic band. 3. Dilated ileum held up by blunt retractor. 4. Adherent appendix.

CAsE 13.-M. G.; female; single. First seen Mareh 2, 1916. Typical symptoms cf chronic intestinal stasis. On examination, found patient anemic; abdominal gas; enteroplusis; intestinal stasis; enlarged and relroverted uterus; tenderness over left 
ovarian region; breasts lumpy at outer quadrants. Operatioł, Nareh 10, 1916: Band from transverse colon to gall bladder; enlarged cecum with retrocecal pouch; appendix adhercnt to wall of divorticulum; last loop of colon fixed in abnormal position by bands; retroverted uterus. Conditions corrected. (See Fig. 8.) August, 1920: Exeellent physical condition; breasts normal.

CASE 14.-H. S.; age thirty; female; single. First seen November 12, 1915. Patient stated she had stomach trouble twelve years; frequent vomiting; lump in pit of stomach; constipation; hearaches. On examination found distinct lumpy condition in upper, outer quadrant right breast; resistance over epigastrium; head of colon tender; marked abdominal gas. Operation, February 25, 1916: Strong band from transverse colon to gall bladder; constriction at duodenojejunal angle caused by band; ileopelvic band with appendiceal tie; dilatation ascending colon; dilatation and rotation of cecum. Conditions corrected, July, 1920: Markedly improved; breasts free of lumpy condition; normal.

CASE 15.-L. S.; age thirty-seven; female; single. First seen May 6, 1907. Complained of hardening and lumpiness of right breast. Advice given as to support of breasts and constipation. In 1916 returned for treatment complaining of discharge of milky serum from both nipples; many lumps throughout breasts; marked leucorrhea and excessive bleeding at periods. On examination found breasts very lumpy with a number of seeming cysts in both mammæ. Large fibroid mass in uterus. Operation, December 27, 1916: Panhysterectomy for multiple fibroids; appendectomy; large, saceulated cecum plicated. Milky secretion in both breasts removed. No breast operation. May, 1920: Patient in good condition; no mammary discharge; breasts normal.

CASE 16.-C. H.; age thirty; female; single. First seen June 16, 1915. Beginning epileptic seizures nine years ago continuing off and on since; more frequent at present time; dizziness; dysmenorrhea. On examination found terminal ileum tender; upper quadrant of left breast Iumpy; uterus congested and rotroverted. Operation, July 1, 1915: Appendix removed; uterus stitched forward. July, 1920: Excellent condition; no epileptic seizures last four years; lumpy condition of breasts ontirely relieved. Embraced Christian Science some months after operation and gives full credit to this form of treatment.

CASE 17.-A. S.; age thirty-two; female; single. First seen July 30, 1919. Six years ago đeveloped severe backaches; palpitation; gas; abdominal pain; marked constipation and lumps in breasts. Operation, August 2, 1919: Abdominal and pelvic adhesions; right ovary fibroid and cystic; adherent appendix; stasis. Conditions corrected. (Note: Had previous laparotomy in 1917.) August, 1920: Twenty-seven pounds gain in weight; marked improvement in physical condition; constipation praetically corrected; no longer any lumps in breasts.

Case 18.-H.C.; age forty-three; female; married. First seen January 10, 1917. In 1905 had operation for acute appendicitis with absecss; sinee then troubled with gas, headaches; constipation. October 1916, sudden attack of indigestion; pain through back; severe vomiting. On examination, found tenderness over gall bladder; slightly enlarged liver; intestiaal stasis; breasts somewhat lumpy. Operation, February 14, 1917: Great omentum thickened and tightly adherent to old wound; cecum rotated and anchored into right side; terminal ileum tightly adherent to posterior abdominal wall; gall bladder fastened to duodenum by bands; fifty-two gallstones; many abdominal bands. Operative conditions corrected as far as possible. August, 1920: Bowels regular; excellent physical condition; no lumps in breasts.

CASE 19.-W. L.; age thirty-four; marricd; female. First seen November 3, 1909. Complained of pain in abdomen; gas; constipation; nervousness. These symptoms fol- 
lowed operation in 1905 , for appendicitis. On examination found large tumor of uterus; movable right kidney; dilated stomach; lumpy condition of breasts. Operation, April 16, 1913. Cecum distended; adherent to right parietal wall, to transverse colon and to peritoneum of right lliac fossa; cystic right ovary; fibroid tumor of uterus; abdominal adhesions. Operative conditions corrected; uterine tumor excised. (See Fig. 9.) August, 1920: General condition good. Lumpy condition of breasts entirely gone.

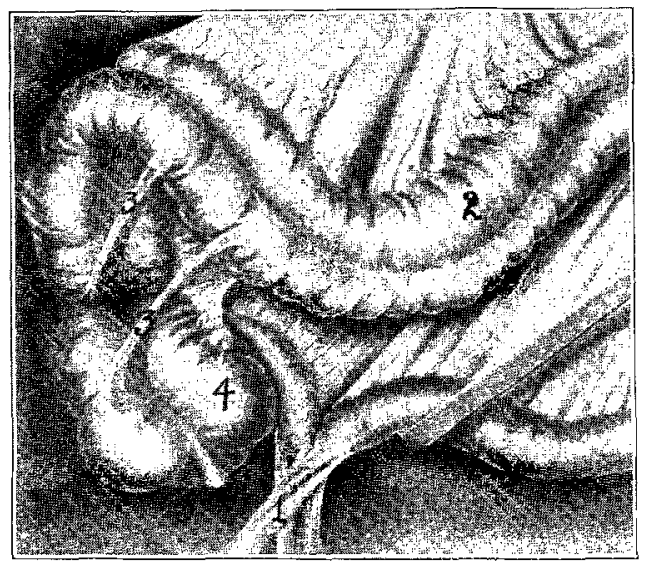

Fig. 9. $-I$. Menpelvic band. 2. Mobile, displaced and twisted ascending colon. 3. Bands kinking and attaching cecum to colon. 4. Dilated cecum. 5. Portion of appendix left after appendectomy- $-(1905)$.

CASE 20.-M. D.; age twenty-six; female; single. First seen November 30, 1915. Troubled with pain in right side; abdominal gas; nausea; marked constipation. Appendix previously removed. On examination, found full, baggy abdomen; large mass in cecal region; lumpy condition in upper, outer quadrant of breasts. Operation, November 30, 1915. Mobile cecum; ileopelvie bands; ileal stasis; transverse colon adherent to ascending colon; band in sigmoid with ovary attached. Conditions corrected. July, 1920: Very well except for dysmenorrhea and at times slight constipation. Breasts normal.

CASE 21.-G. U.; age 28; female; single. First seen Apri1 3, 1915. Usual symptoms of intestiual toxemia; lump in right breast with pain. On examination, found distinct movable tumor, in the imer lower quadrant of right breast, with general lumpy condition of both breasts. Sent to me as cancer of the mamma. Advised early removal of definite tumor, and usual antitoxic treatment. Consented to operation February 9, 1917, and two fibroadenomata were removed from right breast. General treatment was continued as condition of patient was poor. At later operations remored tonsils and adenoics, and diseased right ovary with cystic tube, chromically diseased appendix and a twenty-pound fibroid tumor. April, 1920: Patient in excellent health; lumpy condition of breasts entirely disappeared.

CASE 22.-C. B.* ; age thirty-seven; female; married. First seen February 26, 1914. In November, 1912, noticed small lump right breast; left breast sore; constipation; symptorns of intestinal toxemia. Lump in breast gradually enlarged; declared malignant by surgeon consulted. On examination, found diffuse lumpy condition both breasts; indefinite mass lower, outer quadrant right breast; nipples not retracted.

"Case reported in jart in "The Cancer Problem," p. 202. 
Prescribed usual regime for intestinal toxemia, and kept breasts under careful observation. March 21, 1914: Tumor mass stood out clearly, the surrounding induration having greatly diminished. Operated, removing fibroadenoma, which was proved by pathologic examination. July, 1920: Patient in good health; complete disappearance of lumpy condition of breasts.

CaSE 23.-C. G.; age thirty-seven; female; married. First seen March, 1908. Both breasts distinctly lumpy with three eysts in right one; typical symptoms of intestinal toxemia. Cysts removed, and treatment instituted for constipation and toxemia; urged importance of frequent examination of breasts. Breasts returned to normal and patient remained well until June, 1920, when an acute attack of mus* cular rheumatism, preceded by a prolonged period of constipation, brought to her attention a few small lumps in left breast. Patient fearful of cancer. On examination, found right breast normal; slight lumpy condition in upper, outer quadrant of left breast; no glandular involvment. Reassured patient concerning cancer, and tonic, laxatives and uplifting corset prescribed. July, 1920: Bowels easily regulated with laxatives; both breasts normal; lumps entirely gone.

CASE 24.-E: F.; age thirty-nine; female; married. First seen November 24, 1916. Intestinal indigestion; constipation; gas; lumpy breasts; feared cancer. On examination found tenderness over pylorus; chronic intestinal stasis; lacerated cervix; general lumpy condition both breasts with distinct tumor mass upper, outer quadrant each breast. Operation, December 4, 1916. Divulsion and eurettage; repair of cervix; cyst removed from right breast. Pathologie report indicated benign condition of eyst; therefore, it was decided not to remove an apparent tumor from left breast, but to keep patient under close observation and treat without surgical interrention. Preseribed usual treatment for intestinal toxemia with support for breasts. June, 1920: Breasts perfectly normal; no Iumps; no pain; constipation relieved; intestinal condition markedly improved.

Cs.se 25.-I. S.; age twenty-nine; female; single. First seen Mareh, 1920. Always troubled with constipation. In June, 1918, Iump appeared in lower quadrant left breast; consulted two surgeons both of whom advised radical operation. September, 1918, discovered lump in right breast. December, 1918, both breasts removed, nipples left. Report of pathologist-No malignancy. Consuited me for painful condition of chest wall along line of scar; "feared return of cancer." On examination, found deforming scars; region of breasts negative; clear case of stasis. Prescribed tonic; laxatives; diet, etc. Reassured as to any eancerous condition. September, 1920: With the correction of constipation and reduction of acid-producing diet, patient very much relieved mentally and physically.

\section{SUMMARX}

1. There are definite abnormal changes in the breast tissue, as in the thyroid gland, from intestinal toxemia.

2. Treatment by medical and mechanical means, or surgical intervention for the cure of the intestinal stasis, often means complete return to the normal of the lumpy or toxic breasts.

3. At times it is necessary to remove a definite, localized tumor from the breast, in addition to the above, before the mammary tissue regains its normal texture.

4. Care must be taken that these abnormal changes are not overlooked 
in their early stages; and not diagnosticated as cancer when well developed.

5. In this connection, an important question must be noted: Would an early recognition of a toxic breast and timely and efficient treatment of the underlying intestinal causes, tend to lessen the danger of malignant degeneration? If this is so, then we have here an important contributory factor in the etiology of cancer of the breast.

34 Gramercy Park.

(For discussion, see page 528.)

\section{MISSED ABORTION*}

By Jennings C. Litzenberg, M.D., F.A.C.S., Minneapolis, Minn.

"WISSED abortion" has not received the consideration in this country that it deserves, being generally considered a rare and unimportant condition, while, as a matter of fact, it is of rather common occurrence and results in invalidism, sometimes of a very serious nature. That this subject is neglected in American medical literature is attested by the fact that of 139 references collected, only ten are American and three of these do not mention the term "missed abortion;" they describe the condition as a rarety and, evidently, have never heard of the term first applied by Matthews Duncan ${ }^{\mathfrak{L}}$ who, un. doubtedly, got his idea from Oldham, who in 1847 coined the term "missed labor."

\section{TERMINOLOGY}

"Missed labor" was defined as follows: "Protracted pregnancy is the condition of a woman who has passed 278 days and at least a fortnight more than this. If the child dies in utero there is not then a "protracted pregnancy;" the woman is in a state of "missed labor." This term has become established by usage since 1847, when Oldham ${ }^{2}$ first used it. Duncan ${ }^{1}$ in 1878, recognizing the similarity of the condition of a dead fetus in utero beyond full term and no labor, known as "missed labor," and the condition of a dead fetus before viability and no effort at expulsion, logically used the terms "missed abortion" and "missed miscarriage." The latter term has fallen into disuse and the term "missed abortion" is now applied to all cases of death of the fetus in utero before viability with no effort at expulsion within the usual time of an ordinary abortion.

This naturally brings up the query: When does a woman normally abort after the death of the fetus? Of course the question must be answered more or less arbitrarily. Rhodes" says: "The fetus' is usually aborted a few days after death," which is, I think, ordinarily not

\footnotetext{
* Read at the Thirty-third Annual Meeting of the American Association of Obstetricians, Gynecologists, and Abdominal Surgeons held at Atlantic City, N. J., September 20-22, 1920.
} 